Disponível em:

http://editora.unoesc.edu.br/index.php/race

RACE, Joaçaba, v. 16, n. 2, p. 783-808, maio./ago. 2017

\title{
IDENTIDADE, ARTE E GESTÃO EM PROL DO EMPREENDEDORISMO CULTURAL: SARAU EMPREENDEDOR COMO TECNOLOGIA SOCIAL
}

Identity, art and management for cultural entrepreneurship: entrepreneurship gathering as social technology

Israel Marques Campos

E-mail: israelmcamposs@gmail.com Mestre profissional em Programa de Desenvolvimento e Gestão Social pela Universidade Federal da Bahia; Especializando em Indústrias e Culturas Criativas: Gestão e

Estratégias na Universidade de Lisboa, UL, Portugal; Professor no Centro Interdisciplinar em Gestão Social da Universidade Federal da Bahia.

Eduardo Davel

E-mail: davel.eduardo@gmail.com

Doutor em Administração pela École des Hautes études commerciales de Montréal, Canadá; Doutor (sanduíche) pela Graduate Faculty of Political and Social Science (New School for Social Research), New York; Professor na Escola de Administração da Universidade Federal da Bahia.

Endereço para contato: Avenida Reitor Miguel Calmon, s/n, Vale do Canela, 40110100, Salvador, Bahia, Brasil.

Artigo recebido em 03 de abril de 2017. Aceito em 17 de maio de 2017. 
Resumo

A capacitação de jovens artistas em empreendedores culturais, especialmente no contexto de comunidades periféricas, é uma importante ação para o desenvolvimento tanto dos jovens quanto de territórios potencialmente criativos. No entanto, o empreendedorismo cultural não aparece com frequência no currículo das escolas e as pedagogias de ensino-aprendizagem nem sempre atraem o interesse das novas gerações. Carece-se de pesquisas e propostas práticas sobre o ensino do empreendedorismo cultural nesse contexto. Neste artigo propõe-se uma tecnologia social - “sarau empreendedor”, voltada para um saber prático que possa ser mobilizado em comunidades para fomentar e desenvolver as forças empreendedoras locais no campo da cultura e das artes. O empreendedorismo cultural inclui atividades constituídas a partir da identidade territorial, da coletividade e dos seus impactos socioculturais positivos. Os resultados desta pesquisa contribuem para as pesquisas em ensino-aprendizagem do empreendedorismo cultural, ao proporem uma tecnologia social com potencial de impacto prático no desenvolvimento dos territórios criativos.

Palavras-chave: Empreendedorismo cultural. Sarau empreendedor. Pedagogia artística. Identidade territorial. Tecnologia social.

\section{Abstract}

The education of young artists into cultural entrepreneurs, especially in the context of peripheral communities, is an important action for the development of both young people and potentially creative territories. However, the issue of cultural entrepreneurship does not appear in the curriculum of schools and the prevalent teaching pedagogies are not always attractive to young interests. We lack research and practical proposals on cultural entrepreneurship teaching in such a context. This article proposes a social technology - "entrepreneurial gathering”, oriented to a practical knowledge that may be mobilized by communities in order to promote and develop local entrepreneurial forces in the field of culture and arts. Cultural entrepreneurship includes activities shaped from territorial identity, collectivity and its positive sociocultural impacts. The research results contribute to studies on teaching cultural entrepreneurship as it proposes a social technology with potential for practice-based impact in the development of creative territories.

Keywords: Cultural entrepreneurship. Entrepreneurial gathering. Artistic pedagogy. Cultural identity. Social technology.

\section{INTRODUÇÃO}

A educação empreendedora se tornou uma prioridade para administradores universitários, gestores acadêmicos, gestores públicos e pesquisadores de diversos 
países e culturas (KURATKO, 2005; FAYOLLE, 2007; FAYOLLE, 2010; LOPES, 2010). As pesquisas atuais enfocam a relevância de abordagens baseadas na ação, na experiência e na prática (GIELNIK et al., 2015; HIGGINS; ELLIOTT, 2011; NECK; GREENE; BRUSH, 2014), no intuito de produzirem uma pedagogia menos "passiva” (na qual os estudantes são situados na condição de espectadores passivos da aprendizagem), criando condições de tornar os estudantes participantes ativos e comprometidos (HIGGINS; ELLIOTT, 2011). Entretanto, constatou-se que as pesquisas são muito focadas no nível universitário de ensino do empreendedorismo e que desconsideram as especificidades do empreendedorismo voltado para as atividades da economia criativa (HENRY; BRUIN, 2011; FERREIRA, 2014; REIS, 2008). Além disso, as pesquisas existentes são muito focadas em preocupações analíticas e teóricas. São raras as pesquisas sobre educação empreendedora que fornecem um conhecimento voltado à aplicação prática para além do contexto universitário. Mais raras ainda são pesquisas e práticas que considerem as questões territoriais, identitárias e participativas na educação empreendedora.

Neste artigo formula-se, apresenta-se e discute-se uma tecnologia social: o “sarau empreendedor”. Seu propósito é promover o ensino do empreendedorismo pelas artes, com fundamento na identidade territorial, por meio de um processo de gestão participativa de um evento comunitário. O processo educacional ocorre em dois momentos: durante a pré-produção de um evento comunitário e durante o momento em que esse evento acontece. A tecnologia social (RODRIGUES; BARBIERI, 2008) estrutura-se em três eixos: os conhecimentos sobre empreendedorismo cultural, a pedagogia com base na arte e a gestão participativa de eventos comunitários. A participação é um eixo transversal e integrador da gestão. Os eixos são apresentados nessa ordem, apesar de não terem ordem estabelecida na prática.

Com esta pesquisa propõe-se uma sistematização do saber voltado para a aplicação em comunidades. De um lado, a pesquisa contribui para o campo de pesquisas sobre educação empreendedora trazendo uma reflexão aplicada sobre o ensino específico do empreendedorismo cultural, ao focar em uma “tecnologia social”. Por outro lado, a pesquisa contribui com a prática do empreendedorismo cultural ao fornecer um conhecimento engajado (VAN DE VEN, 2007) que pode ser aplicado por líderes comunitários, gestores, empreendedores, artistas ou quaisquer moradores de comunidades, para fomentar e desenvolver as forças empreendedoras locais no âmbito da cultura e das artes. Assim, os resultados com esta pesquisa fornecem um conjunto de princípios, práticas e conhecimentos que despertam o poder transformador de 
um território, por meio de conhecimentos empreendedores, da pedagogia artística, da gestão de eventos e da ancoragem na identidade territorial.

O público-alvo será designado como “jovens artistas” e "líderes”, por razões didáticas, mas outros profissionais não devem ser excluídos. Algumas questões dão o tom desta pesquisa e do tipo de capacitação que se almeja: quais são as principais práticas para auxiliar o jovem artista no fortalecimento de seu potencial empreendimento cultural? Como o empreendedorismo cultural pode estabelecer bases sólidas em um território periférico para a capacitação de novos profissionais e catalisar o desenvolvimento local? Quais ações os líderes e os jovens participantes podem sugerir para o processo de aprendizagem do empreendedorismo cultural por meio das artes e para a realização do sarau empreendedor?

O formato de sarau tem sido apropriado por diversos grupos de artistas de bairros populares no Brasil. ${ }^{1}$ Atualmente, tem sido mais utilizado no contexto da literatura dos bairros populares, sendo reconhecido pelo forte compartilhamento de trabalhos ligados à identidade territorial (PEÇANHA, 2012; TENNINA, 2013). O termo sarau pode ser trocado por “feira”, “espetáculo” ou “festa”, de acordo com as necessidades da comunidade, que deve definir, coletivamente, o formato e o nome do “sarau empreendedor”, sempre considerando o propósito socioeducacional da atividade. Além de formular, apresentar e discutir a tecnologia social do sarau empreendedor, também serão apresentados exemplos para facilitar o entendimento dos conceitos.

O sarau empreendedor é uma tecnologia social na medida em que se caracteriza como metodologia replicável, desenvolvida na interação com a comunidade e buscando trazer efetivas soluções de transformação social (DAGNINO, 2014). É uma forma de incentivar o sonho empreendedor coletivo (DOLABELA, 2003), com potencial de transformar várias carreiras existentes em uma comunidade. O sarau empreendedor orienta-se por várias questões: como o ensino de empreendedorismo cultural pode interessar, capacitar e estimular, de fato, os jovens? Como essa capacitação pode desenvolver territórios potencialmente criativos e multiplicar empreendedores culturais?

Do ponto de vista de sua contribuição prática, este artigo se justifica pela demanda de capacitação e estímulo de empreendedores de cultura no contexto de bairros periféricos, considerando as referências e práticas identitárias locais. Para o ensino do empreendedorismo cultural, uma área fundamentalmente coletiva, criativa, inova-

\footnotetext{
${ }^{1}$ Para mais informações, ver Sarau da Onça (2017), Francisco Neto (2012), Vianna (2012), Piratas... (2016) e Catraca Livre (2017).
} 
dora e que lida com aspectos constituintes da identidade territorial dos sujeitos, uma capacitação artística e que entretém, como o sarau, fornece leveza e dinâmica para a aprendizagem dos conhecimentos inerentes à prática empreendedora no âmbito da cultura, quando se pensa que os jovens artistas são o nosso público-alvo (ALMEIDA; PAIS, 2013). Constata-se que muitos artistas não se veem como empreendedores da cultura e consideram impossível "viver de arte” (CAMPOS, 2016).

A metodologia da pesquisa é qualitativa e as informações foram coletadas por meio de entrevistas semiestruturadas com empreendedores culturais e participantes de uma experiência de realização de um sarau empreendedor. O conteúdo do material empírico foi analisado (COLBARI, 2014) e gerou a tecnologia desenvolvida e apresentada neste artigo. Entrevistas e observações no campo foram realizadas ao todo com 11 empreendedores musicais, 23 estudantes, 15 jovens da comunidade e quatro líderes sociais e culturais da comunidade do Nordeste de Amaralina, em Salvador, Bahia. O Nordeste é um território que abarca cinco bairros distintos (Nordeste de Amaralina, Santa Cruz, Vale das Pedrinhas, Chapada do Rio Vermelho e Nova República) mas, territorialmente, próximos. Apesar de ser um território com fortes manifestações culturais como o samba junino e o seu carnaval típico, o território sofre com problemas relacionados ao desemprego, à baixa renda, a escolas e postos de saúde desestruturados, a esgotos a ceú aberto e ao forte envolvimento com tráfico de drogas entre os jovens. ${ }^{2}$

A primeira versão da experiência sarau empreendedor ocorreu dentro desse contexto, rico em manifestações e iniciativas socioculturais. ${ }^{3} \mathrm{O}$ processo de realização do sarau aconteceu durante cinco meses, com o objetivo de ensinar conhecimentos relativos ao empreendedorismo cultural por meio das artes e da gestão participativa de eventos comunitários. Foi produzido um evento de caráter comunitário voltado para o estímulo e a capacitação do empreendedorismo cultural, com fundamento na identidade territorial. Essa aplicação do sarau promoveu capacitação para os jovens participantes por meio dos conhecimentos empreendedores apresentados de formas artísticas (encenações, curta-metragem, blogs, palestras e oficinas), durante toda a experiência de planejamento e execução do sarau.

\footnotetext{
${ }^{2}$ Para mais informações, ver Associação de Moradores no Nordeste de Amaralina (2017).

${ }^{3}$ Para mais informações, ver DM de boa Facebook (2017) e Quabales (2017).
} 


\section{IMPORTÂNCIA DO EMPREENDEDORISMO CULTURAL}

Neste artigo considerou-se o empreendedorismo cultural como um misto de empreendedorismo social, empreendedorismo coletivo e identidade territorial. Ter em mente as dimensões sociais, coletivas e identitárias é fundamental para os líderes culturais aprenderem e ensinarem os conhecimentos relativos ao empreendedorismo cultural. O empreendedorismo social é um elemento importante a ser considerado em razão da sua capacidade e objetivo de gerar transformações sociais (CALAS; SMIRCICH; BOURNE, 2009; HJORTH, 2013; STEYAERT; HJORTH, 2006; SWEDBERG, 2000). Entende-se o empreendedor social como agente que possui como agenda as mudanças sociais, a multiplicação das riquezas dentro do sistema econômico vigente (CASAQUI, 2015) e com a mobilização da criatividade proporciona inovações sociais (CASAQUI, 2016). A dimensão coletiva do empreendedorismo à condução de um processo, voltado geralmente para empreendimentos de caráter social, com um conjunto de jovens que compartilham atribuições e decisões (SCHMIDT et al., 2016). De acordo com a ideia desse tipo de empreendedorismo, os princípios coletivos são o fundamento para o desenvolvimento de todo o processo, do planejamento à execução (MALO; RODRIGUES, 2006).

O empreendedorismo envolve um processo de criação e absorção do que há de valor na cultura da comunidade (ANDERSON, 2000), considerando cultura como recurso retórico, processo de criação e consumo simbólico (DAVEL; CORÁ, 2016). Nada impede que um líder desponte como empreendedor, em um trabalho coletivo com a comunidade, logo, a liderança pode ser exercida individualmente respeitando o espaço em que ela ocorre e os envolvidos no projeto. Tanto o empreendedorismo social quanto o coletivo, no contexto comunitário, fazem sentido quando os líderes consideram a identidade territorial, ou seja, quando o empreendedorismo visa absorver o conjunto de práticas, hábitos, trabalhos, artes e qualquer outra produção que singularize a comunidade e auxilie no desenvolvimento local. A identidade territorial não é algo dado, mas um processo intencional e político, traduzindo-se em uma política de gestão construída pela comunidade (DAVEL; SANTOS; DANTAS, 2016). Nesse sentido, a identidade territorial é o resultado da interação dos moradores com o bairro e com o mundo, articulada dentro de uma estratégia coletiva a longo prazo. A identidade territorial é responsável por agregar valor, estabelecer distinções, enaltecer as singularidades e potencializar o bairro em sua marca cultural.

Empreendedores culturais mobilizam recursos, de forma criativa e inovadora, promovendo a mudança social e a emancipação coletiva (CALAS; SMIRCICH; 
BOURNE, 2009; DAVEL; CORÁ, 2016; STEYAERT; HJORTH, 2006; SCOTT, 2012; RINDOVA; BARRY; KETCHEN, 2009; LOUNSBURY; GLYNN, 2001). O artista é frequentemente interpelado a agir como empreendedor cultural (LINDQVIST, 2011; RENTSCHLER, 2007). No contexto de bairros periféricos, o empreendedorismo cultural pode ser apreendido como resultado do empreendedorismo social, pelo seu caráter de transformação social mediante a cultura, o coletivo, o trabalho em redes e a ancoragem na identidade territorial.

Dessa forma, o empreendedorismo cultural pode ser entendido e valorizado pelos jovens que trabalham com arte e cultura. Ao aprenderem conhecimentos relativos ao empreendedorismo voltado para a área cultura, em formatos afinados com linguagens artísticas, os jovens poderão aprimorar suas carreiras. Assim, o bairro poderá se desenvolver de forma mais sustentável, ao mesmo tempo que participa de ações coletivas em prol de um território. Ações voltadas para o empreendedorismo cultural podem contribuir para reduzir a violência entre os jovens, o desemprego e a pobreza, além de fortalecer a economia criativa no bairro. Conjunto de atividades fundamentadas na criatividade, a economia criativa inclui várias escalas territoriais (cidades, territórios e bairros) e aspectos (culturais, econômicos e sociais) (HENRY; BRUIN, 2011; FERREIRA, 2014; REIS, 2008).

\section{DESAFIOS DO ENSINO-APRENDIZAGEM DO EMPREENDEDORISMO CULTURAL POR MEIO DAS ARTES}

O sarau empreendedor visa suprir uma grande carência no campo do ensino do empreendedorismo: parcela considerável dos líderes de comunidades e jovens artistas possuem poucos conhecimentos sobre o empreendedorismo cultural, e os recursos pedagógicos para o seu ensino não são sempre adequados. Percebe-se que o esquema tradicional de ensino (estudantes sentados, docentes em pé em uma sala fechada) vem perdendo força. Portanto, um evento comunitário do tipo aqui proposto apresenta-se como estratégia pedagógica dinâmica e divertida, estimulando o aprendizado dos jovens artistas. Os padrões da educação formal raramente incluem conteúdo sobre empreendedorismo no currículo e, quando incluem, não formam potenciais empreendedores de forma atrativa, inovadora. Esses padrões desconsideraram a identidade territorial como fundamento para o processo educacional, nem sempre tendo impacto estimulante no jovem (DUARTE JUNIOR, 2008; BONDÍA, 2002).

Pensando nas especificidades do empreendedorismo cultural e do público jovem, o sarau empreendedor favorece uma aprendizagem em contexto informal 
(LIVINGSTONE, 1999) e experiencial. Os processos educativos requerem a consideração da realidade local do indivíduo (FREIRE, 2011). Considerar e tratar sobre empreendimentos territoriais, por exemplo, é um ótimo início para envolver os jovens artistas no ensino do empreendedorismo cultural. O sonho empreendedor (DOLABELA, 2003) é outro dispositivo interessante para o ensino-aprendizagem do empreendedorismo cultural, pois ao estimular o compartilhamento dos sonhos de cada jovem participante é possível que os sonhos sejam agregados, estimulando a participação dos jovens no processo de aprendizagem, somando às ideias para o sarau empreendedor e estimulando as carreiras profissionais além do sarau. A educação deve ser vista como um processo relacional, nunca apenas da parte do jovem músico disposto a aprender sobre o empreendedorismo cultural ou dos líderes que podem ensinar os conhecimentos no processo de realização do sarau. Em cada relação, novos desafios irão aparecer. Não existe receita pronta.

Um desafio envolvendo o ensino-aprendizagem do empreendedorismo cultural consiste na grande quantidade de conhecimentos necessários para a capacitação nessa área e na execução da pedagogia artística. Uma forma de enfrentar esse desafio é suavizar e tornar o conhecimento mais atraente para os jovens, por meio de exemplos práticos, autores, manuais e documentos sobre os temas que dialoguem de forma mais direta com o jovem e principalmente mediante a aplicação da pedagogia artística. Outra forma de enfrentamento é fornecer uma visão geral do tema e se aprofundar mais nos assuntos que os jovens se interessam para desenvolver suas carreiras e suas comunidades. Para lidar com os desafios, é necessário que os líderes comunitários se conscientizem de que é possível incluir diversas temáticas do conhecimento empreendedor nas ações artísticas e que todas essas ações valem tanto para a pré-produção do sarau empreendedor quanto para o momento de sua apresentação.

Outros desafios são relacionados à escolha adequada das linguagens artísticas para o ensino do empreendedorismo (entendendo que o ensino-aprendizagem faz parte de todo o processo de pensar e executar o sarau), a capacidade de estimular constantemente a criatividade dos jovens artistas e manter o ensino-aprendizagem um processo dinâmico. Ao longo de todo o processo, é necessário considerar a realidade local, estimular o trabalho coletivo, considerar as linguagens artísticas afinadas ao público-alvo, proporcionar aprendizagem durante todo o processo de ensino, compartilhar o sonho coletivo, ouvir e tomar decisões de forma compartilhada. 


\section{SARAU EMPREENDEDOR: UMA TECNOLOGIA SOCIAL DE ENSINO-APRENDIZAGEM}

O sarau empreendedor é uma prática que pode capacitar para o empreendedorismo cultural, estimular o potencial de emancipação, trabalhar com a sociabilidade (DANDRIDGE, 1986; HJORTH, 2004; HJORTH, 2013), promover a consciência lúdico-identitária (BELO; SCODELER, 2013) e transformar a festa em força coletiva integradora (GUARINELLO, 2001). Nesta seção apresentam-se os processos, as práticas e as instruções para que os líderes consigam aplicar a tecnologia social em sua comunidade. São os conhecimentos empreendedores, a pedagogia artística e a gestão do evento comunitário. A tecnologia social do sarau é representada na Figura 1, em que a identidade territorial e a participação são forças transversais. É a partir da identidade territorial que os conhecimentos empreendedores serão adaptados conforme a realidade do bairro, que as linguagens artistas serão escolhidas e que a gestão de eventos ocorrerá com participação.

Figura 1 - A tecnologia social do sarau empreendedor

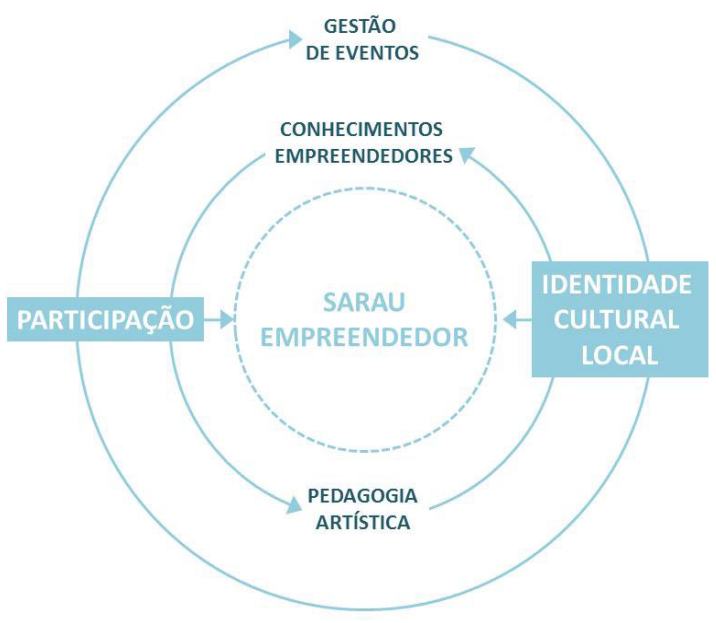

Fonte: os autores.

Os conhecimentos para o empreendedorismo representam os conteúdos do currículo. São os conhecimentos imprescindíveis que cada jovem artista deve se apropriar para desenvolver sua carreira e sua comunidade. Não adianta que esses conhecimentos sejam apresentados da forma tradicional. A pedagogia artística é como acontecerá o processo de ensino-aprendizagem. Os conhecimentos serão apresentados 
aos participantes e construídos de forma coletiva por meio das linguagens artísticas, fazendo com que cada assunto fique mais atrativo e instigante para os jovens artistas. A gestão de eventos faz acontecer o evento comunitário na prática. São conhecimentos sobre como administrar o evento cultural de forma participativa em prol da comunidade. O sarau empreendedor é o momento que reúne todas essas dimensões, com ensinos sobre empreendedorismo, mediante as artes e a gestão de eventos participativa, com fundamento na identidade territorial. A conexão entre esses diferentes elementos do sarau é o diferencial da tecnologia social a que se propõe neste artigo.

\subsection{CONHECIMENTOS DO SARAU EMPREENDEDOR}

Os conhecimentos do sarau empreendedor, para que sejam de fato aprendidos e ensinados, devem ter como fundamento alguns princípios, estratégias e questões. Para cada linguagem artística, o conhecimento pode ser alterado, visto que cada linguagem tem características e necessidades próprias. Para empreender na música, por exemplo, é necessário conhecer a maior força de um artista da música na contemporaneidade. Essa força é o show, pois “com a crise da indústria fonográfica, o show se afirma como principal fonte de renda do artista” (SALAZAR, 2015). Essa consideração é muito importante para pensar que tipo de capacitação buscar para os empreendedores potenciais. Se o show é a fonte mais importante para uma carreira artística no âmbito da música, é importante que as práticas e técnicas empreendedoras para a realização de um show sejam fornecidas aos jovens.

Um conhecimento essencial para todo empreendedor cultural é saber trabalhar com o começo, o meio e o fim de um edital. Por meio do financiamento cultural, da elaboração de projetos, da prestação de contas (incluindo conhecimento sobre fluxo de caixa), espera-se que o jovem artista empreenda sua arte com base no apoio público, privado e/ou coletivo. O financiamento cultural vem com a missão de apresentar aos jovens artistas as diversas possibilidades que eles possuem de bancar espetáculos, produções, enfim, suas carreiras. Empresas e órgãos públicos podem ser convidados a apresentar seus editais em formatos audiovisuais, de palestra ou em uma roda de conversa. Uma exposição com nomes dos financiadores culturais, possibilidades de financiamento e endereços eletrônicos pode ser realizada no espaço do sarau para a consulta dos jovens. Um parceiro pode apoiar com material escrito a ser distribuído ao final do sarau para os jovens. Recursos coletivos apresentados mediante plataformas virtuais também são conhecimentos importantes, pois são democráticos e de fácil acesso para os jovens artistas. 
Os líderes que aplicarem a tecnologia social devem se ater ao conhecimento do empreendedorismo cultural e suas dimensões (social, coletiva e identitária), para que esse conhecimento alcance os jovens artistas. Além de um empreendimento cultural na própria comunidade, para apresentações durante o sarau empreendedor, os líderes podem construir uma rede empreendedora, convidando jovens artistas de outras comunidades. Essa ação pode incentivar a multiplicação do sarau empreendedor, estimulando mais jovens e líderes a realizá-lo em outros locais, desenvolvendo mais carreiras e comunidades. A rede empreendedora cultural acontece ao serem convidados artistas e empreendedores culturais de outros bairros, cidades ou países para participarem do sarau. Um exemplo de rede empreendedora é a prática da Transforma, ${ }^{4}$ empresa que trabalha com projetos socioculturais com jovens em uma cidade periférica de Lisboa, e do Neojiba, ${ }^{5}$ que promove intercâmbios de crianças e jovens de diferentes instituições com o núcleo. Esse tipo de rede pode promover um sarau empreendedor mais rico, colaborando no sentido de que não pesa sob um único indivíduo todos os pré-requisitos para ser empreendedor cultural, para ensinar o empreendedorismo cultural e pela realização do sarau, além de permitir uma possível mobilidade dos artistas por diferentes territórios.

A capacitação voltada ao empreendedorismo deve se ater também ao conhecimento que se refere ao marketing do trabalho artístico. Trata-se de apresentação das mídias sociais, como funcionam e estratégias de divulgação da música, tendo como exemplos facebook, twitter, youtube, spotify e instagram. Deve-se incluir, também, a participação de um assessor de imprensa como aliado de divulgação de shows e turnês do artista. Mostrar aos artistas que investir na comunicação e divulgação das suas artes é possível com pouco dinheiro e de forma eficaz.

\subsection{PEDAGOGIA ARTÍSTICA DO SARAU EMPREENDEDOR}

A arte, objeto de desejo de todos os jovens artistas e de jovens de forma geral, parece o instrumento mais eficaz para o ensino-aprendizagem do empreendedorismo cultural. Percebe-se que muitos jovens são frequentadores de festas, eventos de lazer, saraus, consumidores de jogos eletrônicos, esportes, artes e outras formas de expressões criativas. Essas atividades dinâmicas, artísticas, criativas e lúdicas são

\footnotetext{
${ }^{4}$ Para mais informações, ver Transforma (2017).

${ }^{5}$ Para mais informações, ver Neojiba (2017).
} 
importantes para o público jovem. O sarau empreendedor considera a arte, pois esta fornece elementos encorajadores da criatividade (MAINEMELIS; RONSON, 2006), uma das principais características demandadas do empreendedor. A pedagogia artística visa criar momentos de descontração com aprendizado, em que os indivíduos podem fortalecer suas identidades individuais e perceber as compatibilidades coletivas, potencializando a identidade territorial.

Na etapa de planejamento (pré-produção) do sarau empreendedor espera-se que os líderes comunitários construam conhecimentos do empreendedorismo por meio das artes. Como possibilidades artísticas se pode pensar na música, teatro, cinema, dança, fotografia, artes plásticas e literatura, mas outra linguagem artística pode ser incluída, considerando as especificidades que cada linguagem pode demandar dos líderes. E se os líderes não dominam ou não têm nenhum conhecimento dessas práticas artísticas? Eles podem buscar subsídios em trabalhos específicos de cada área artística antes de começar o ensino do sarau empreendedor e estabelecer parcerias com artistas que possam colaborar no processo de ensino-aprendizagem, para auxiliá-los no ensino do empreendedorismo no decorrer da preparação do sarau.

Como ensinar empreendedorismo por meio das artes e seus processos criativos? Como apresentar os conhecimentos conjugando-os com arte? Decidir o formato do sarau empreendedor é um momento importante da tecnologia social. Ela pode ser pensada para o período de seis meses de capacitação dos jovens artistas envolvidos desde o começo da tecnologia, até o momento em que se apresenta o sarau empreendedor. A carga horária presencial sugerida é de quatro horas, a contar com a demanda dos participantes e líderes, bem como com o bom senso em relação à situação de cada pessoa envolvida. O número de pessoas envolvidas desde o começo do processo depende também das demandas do evento e da comunidade. Uma sugestão para auxiliar o líder nessa questão é dividir as atividades por grupos, limitando o número de participantes. As sugestões de atrações e ações de caráter puramente artístico ou de pedagogia artística para o ensino do empreendedorismo possuem fundamentos em práticas artísticas de muitos jovens de bairros periféricos.

A ideia da pedagogia artística para o empreendedorismo é unir a forma (artes) com o conhecimento (empreendedorismo) para que o ensino seja mais prazeroso, criativo e atraente para líderes e jovens artistas, pois se os jovens têm familiaridade com as artes, mas não têm com o empreendedorismo, o conhecimento fica muito mais próximo e convidativo. A pedagogia artística para o ensino do empreendedorismo auxilia os líderes a coconstruírem o conhecimento, desenvolvendo uma gestão participativa para a realização do sarau empreendedor. 


\subsection{GESTÃO DO EVENTO COMUNITÁRIO}

A gestão de eventos comunitários pode ser pensada a partir de um dos elementos do empreendedorismo cultural, o empreendedorismo coletivo, pois assim como esse tipo de gestão, o empreendedorismo coletivo é realizado em torno de um evento para um bem comum, com objetivos comuns (MALO; RODRIGUES; 2006). Um evento compartilhado não pode ser construído senão de forma coletiva e o menos hierarquizada possível. Isso quer dizer que dos líderes que já realizaram três eventos comunitários aos líderes que nunca tiveram experiências na área, todos deverão ser ouvidos. O processo de escuta é ativo, permanente e fundamental.

A gestão de um evento, com consideração da efetiva participação, pode então ser definida como aquela em que todos os participantes são considerados quanto às suas sugestões, críticas e demandas. A gestão desse tipo de sarau, com fundamento na identidade territorial, ganha outra dimensão, pois a voz local é o principal guia para a realização e a gestão do evento. Ela visa, então, ao desenvolvimento local, sempre em um tempo contínuo de construção (BRANDÃO, 2011).

A gestão do sarau pode dinamizar comunidades, contribuindo com a melhoria das práticas de gestores comunitários que têm apreço pela cultura e pela identidade da comunidade. Cada comunidade possui suas vocações e interesses específicos. Seja qual for a expressão que uma comunidade disponha (gastronomia, música, artesanato, arquitetura, esportes, entre outras), ela pode ser um destaque no sarau, apresentar-se como um trabalho diferenciador.

A autonomia e a diversidade dos envolvidos no projeto são forças que garantem uma gestão de eventos participativa. Autonomia, pois cada participante do projeto pode, com liberdade, desenvolver melhor suas ideias e tornar o evento cada vez mais atrativo. A diversidade é importante porque quanto mais se somam talentos e esforços, torna-se mais provável atingir um melhor evento, atendendo e ampliando seus atrativos. A gestão, o conhecimento, a pedagogia, orquestrados pela identidade territorial, dão vitalidade ao sarau empreendedor. A gestão, sem escuta e participação, tende a produzir eventos sem conexão com a comunidade, por isso a escuta é tão importante para que a gestão de eventos seja efetivamente participativa. É nesse processo de escuta que se motivam os participantes para participarem e serem parceiros no processo educativo do sarau empreendedor.

Por que temos que fazer um sarau empreendedor para o empreendedorismo? Quais seriam os objetivos de motivar os jovens? Como motivar os jovens? Quais são as formas? Essas questões fazem parte das dimensões participativas que podem ocor- 
rer na aplicação da tecnologia social. O fundamento de gostos, percepções e histórias dos jovens na comunidade, que constituem a identidade territorial, representa uma fonte de engajamento para os jovens.

A motivação para os jovens artistas pode perpassar o fator inovador, próximo ao gosto e à identificação dos jovens. No processo de motivação para o início da realização do sarau empreendedor, é possível apresentar aos jovens propostas de minisshows, performances e apresentações artísticas para o ensino do empreendedorismo cultural, nas linguagens artísticas em que os líderes tenham domínio. Assim, durante a apresentação do sarau empreendedor, esses jovens e outros participantes poderão proporcionar sensações ao público: vínculo a um espaço de sociabilidade e entusiasmo pela necessidade do empreendedorismo cultural e uma atração no palco que estimule o empreendedorismo por meio das artes. Assim, ampliou-se a ideia de "grade curricular”, de “disciplinas” (formatos que possuem uma noção de aprisionamento para o jovem) para incluir a possibilidade de participação no formato do ensino, no sarau, da criatividade e da inovação ao longo da capacitação.

Mediante a demonstração para os jovens do quanto será interessante estar em um lugar com empreendedores e personalidades ligadas à cultura, a presença de vários jovens do bairro e de outros bairros desperta o desejo em todos os envolvidos. $\mathrm{O}$ sarau traz a possibilidade de levar aos jovens técnicas, procedimentos e caminhos possíveis para empreender na área da música, além de outros conhecimentos possíveis.

Afinal, que tipo de sarau empreendedor queremos para os jovens artistas de nosso bairro? Para os líderes do bairro pensarem na adequação do sarau empreendedor para a realidade do local (contextualização), eles necessitam identificar todos os aspectos do bairro, a exemplo de jovens artistas, áreas artísticas predominantes, empreendedores existentes (no âmbito da cultura ou não), empreendedores potenciais (no âmbito da cultura ou não), necessidades, histórico de saraus, eventos, festas e histórico de atividades de capacitação. No início, os líderes devem se ater às expressões artísticas e/ou empreendedoras da comunidade. Reconhecer os valores dos jovens artistas e, em seguida, incluir esses valores na aprendizagem e realização do sarau empreendedor é primordial para o sucesso do sarau. Não adianta querer fazer um sarau empreendedor pensando em uma cultura global, padronizada, desconsiderando a identidade territorial. Sabe-se que há uma hibridização das identidades (HALL, 2006), mas se enfatiza que a valorização da identidade territorial, o que a comunidade tem de bom, é essencial.

Durante e depois da realização do sarau, deve-se praticar a avaliação, dentro do princípio segundo o qual a participação é sempre coletiva, colaborativa e crítica. 
Sua importância acontece para a melhoria da próxima edição do sarau, bem como para o crescimento dos jovens artistas como empreendedores culturais. A avaliação formativa deve ocorrer o mais rápido possível, em alguns momentos estratégicos durante o período de preparação e logo após a apresentação do evento, para que as percepções positivas e críticas não sejam apagadas.

\section{SARAU EMPREENDEDOR EM NORDESTE DE AMARALINA: UMA EXPERIÊNCIA ILUSTRATIVA}

Para facilitar o entendimento da aplicação do sarau empreendedor, apresentam-se ilustrações dos conhecimentos e da pedagogia e a gestão de eventos. Trata-se de uma experiência de realização do sarau empreendedor no território de Nordeste de Amaralina, em Salvador, Bahia.

\subsection{CONHECIMENTOS DO SARAU EMPREENDEDOR}

No sarau empreendedor, os conhecimentos do empreendedorismo cultural foram escolhidos após escutar líderes sociais, culturais e jovens artistas. Os conhecimentos escolhidos tratavam de legalidade, carreiras, recursos públicos e privados, recursos coletivos, produção e marketing. Cada conhecimento foi compartilhado e construído com os jovens que participaram do início ao fim do sarau, incorporando-os nas apresentações feitas no dia do sarau para toda a comunidade. Um conjunto de eixos temáticos se consolidou como central e definitivo: identidade, carreiras, projeto, marketing, financiamento e legalidade. A identidade empreendedora, bem como o projeto e o financiamento sendo trabalhados de uma forma geral e não apenas no âmbito da produção, são conhecimentos mais amplos e necessários para a educação empreendedora dos jovens envolvidos.

\subsection{PEDAGOGIA ARTÍSTICA DO SARAU EMPREENDEDOR}

Uma grande referência para a aplicação da pedagogia artística no Nordeste de Amaralina é o projeto do Neojiba, Núcleos Estaduais de Orquestras Juvenis e Infantis da Bahia, que realiza diversas ações com foco no desenvolvimento social, formação musical, prática de orquestra e coral, apresentações públicas, intercâmbios 
pedagógicos, entre outras importantes ações. ${ }^{6}$ A pedagogia, com base nas artes para o ensino do empreendedorismo no sarau empreendedor, é um dos principais elementos que farão do sarau um evento forte pelo processo educativo pelos quais passarão os jovens artistas durante todo o percurso de planejamento do sarau e os estímulos ao empreendedorismo cultural fornecidos com atividades no dia em que ocorrer o sarau. Todas as ideias devem ser alimentadas, a criatividade conta muito para que o projeto funcione, estimulando o desenvolvimento da economia criativa do local.

Para aplicar a pedagogia artística, foram propostas seis linguagens artísticas: música, cinema, artes visuais, dança, literatura e teatro. Foram sugeridas as seguintes ações artísticas e pedagógicas: curta-metragem sobre depoimentos de narrativas empreendedoras, grafite, músicas compostas e produzidas para o sarau empreendedor, breaking/B-boying de caráter educativo, apresentação de DJs, cineclube com debate, papo com empreendedor, contação de histórias empreendedoras, performances poéticas, exposição de fotografias e de artes visuais, apresentações de dança e teatro sobre empreendedorismo musical.

\subsection{GESTÃO DE EVENTOS DO SARAU EMPREENDEDOR}

Para iniciar o processo do sarau, os líderes e jovens do território se reuniram com um grupo da universidade para pensarem coletivamente na visão, na motivação e nos objetivos do sarau. Algumas questões foram importantes nesse processo de planejamento do evento: por que temos que fazer um sarau empreendedor para aprender e ensinar o empreendedorismo por meio das artes? Por que motivar os jovens a participarem do processo? Como vamos produzir o nosso sarau? O que precisamos fazer para que ele aconteça? Quais são os nossos sonhos? De que precisamos para alcançá-los? O que precisamos saber sobre nossa identidade para dar sentido ao sarau empreendedor? Que sarau empreendedor queremos para os empreendedores culturais de nosso bairro? O que aprenderemos com o sarau empreendedor? O que o sarau melhorará para a sua carreira artística? O que o público que comparecerá ao dia do sarau aprenderá? O que a comunidade ganhará com o sarau?

\footnotetext{
${ }^{6}$ Para mais informações, ver Neojiba (2017).
} 


\subsubsection{Como Motivar para o Sarau Empreendedor? Que Sarau Empreendedor Queremos?}

A consideração do sonho individual e coletivo como fatores fundamentais para o sarau empreendedor se apoiou em práticas similares na cidade, como a Ong Pracatum, ${ }^{7}$ no bairro do Candeal, a Fábrica Cultural, ${ }^{8}$ no bairro da Ribeira e o Ilê Ayê, ${ }^{9}$ no bairro da Liberdade. Na aplicação do sarau no Nordeste de Amaralina, mediante rodas de conversas com líderes sociais e culturais do território e com os jovens artistas, ouviram-se relatos, desejos e dificuldades que cada um passava na sua vida de forma geral e especificamente na sua carreira artística. Essas rodas de conversas ocorriam durante todo o processo do sarau, para pensar e repensar se o que estava sendo ensinado, aprendido e planejado estava de acordo com a visão de sarau com fundamento na identidade territorial.

Na realização da gestão de um evento comunitário os líderes enfrentam o desafio de motivar os jovens para o sarau empreendedor. Reconhecer seus talentos e atividades e logo apresentar a linguagem artística como forma de aprendizado para a realização do sarau é um diferencial. A gestão participativa tem o intuito de promover mudanças coletivas em carreiras de artistas, bem como de desenvolver comunidades. Foi percebido na aplicação da tecnologia no Nordeste que esse tipo de gestão para um evento comunitário possui vantagens e desafios apresentados, sendo importante o líder de uma comunidade que aplicar a tecnologia ter conhecimento de tais aspectos.

As vantagens são: motivação de trabalhar com artistas do próprio bairro; realização de novos contatos e parcerias profissionais; construção coletiva do que seria o sarau empreendedor; identificação de aspectos da realidade local, de jovens artistas, estilos artísticos do bairro, empreendedores já existentes (no âmbito da cultura ou não), empreendedores potenciais (no âmbito da cultura ou não), necessidades, histórico de eventos comunitários e histórico de atividades de capacitação por meio das artes; e identificação e estímulo do sonho individual e coletivo para a fundamentação do sarau empreendedor.

Os desafios identificados são: conseguir congregar datas, horários dos jovens artistas, bem como motivar os jovens; administrar os conflitos que um trabalho em

\footnotetext{
${ }^{7}$ Para mais informações, ver Pracatum (2017).

${ }^{8}$ Para mais informações, ver Menezes (2017).

${ }^{9}$ Para mais informações, ver Ilê Aiyê Oficial (2017).
} 
grupo pode apresentar, como divergências de opiniões, possíveis ofensas, alertar os jovens que esse tipo de situação pode acontecer para lidarem da melhor forma; ressaltar a importância da dimensão da participação para o aprendizado e a transformação nas carreiras de cada jovem artista; e engajar os jovens no projeto mediante a possibilidade de escolha de quais papéis cada um irá assumir na gestão do sarau.

\subsubsection{Como Planejar o Sarau Empreendedor}

Um cronograma foi esboçado, de forma participativa, de acordo com as etapas operacionais da gestão de eventos para a realização do sarau empreendedor. No primeiro mês ficaram definidas as seguintes ações: conhecer o território, suas potencialidades, os jovens artistas, os empreendedores culturais, os empreendedores locais; filtrar quais profissionais e moradores do território podem se envolver na produção do sarau empreendedor e definir com eles o desenho do cronograma de planejamento, produção e avaliação do sarau empreendedor; definir as mídias sociais que podem ser utilizadas para a divulgação. No segundo e terceiro meses, algumas ações foram estabelecidas: selecionar, além dos parceiros, recursos públicos, privados e coletivos para financiar o sarau empreendedor. No quarto e quinto meses, priorizou-se: a pré-produção e realização do sarau empreendedor com os conhecimentos e formatos pertinentes; a divulgação do sarau empreendedor em mídias sociais; e, por fim, no sexto mês, ocorreu a avaliação do sarau empreendedor dos jovens participantes e dos parceiros atuantes.

\subsubsection{Como Avaliar o Sarau Empreendedor}

Uma sugestão de registro das avaliações é uma filmagem em que os quatro tipos de envolvidos no sarau sejam entrevistados: os líderes, os jovens artistas que participaram desde o princípio, os jovens artistas que participaram somente da apresentação do sarau e o público geral. Com essas respostas, é possível avaliar o que funcionou e o que pode ser melhorado no próximo sarau, se for o caso. Outra utilização para a filmagem seria a utilização desse material como forma de retroalimentar o ciclo, servindo de mobilização de novos jovens, posteriormente, em novas ações, sobretudo para manter a rede empreendedora.

Após o sarau, a equipe que participou do início ao fim da preparação ao dia do sarau se reuniu para conversar sobre: o que podemos melhorar para o próximo 
sarau? Podemos fazer outro formato, como feira, festa ou um outro tipo de evento na próxima vez? Todos os objetivos foram cumpridos? Se algum objetivo não foi cumprido, o que faltou? Qual é a avaliação dos moradores que construíram a tecnologia social?

\section{DISCUSSÃo E CONCLUSÃo}

O trabalho se propôs a formular uma tecnologia social que facilite e estimule os jovens, por meio das artes, no processo de aprendizagem e assimilação dos conhecimentos do empreendedorismo cultural valorizando as forças da identidade territorial e da ação coletiva. Para alcançar o objetivo, nesta pesquisa discutiram-se as ideias de educação mediante as artes, o empreendedorismo cultural, a gestão de eventos, a participação e a identidade territorial. A tecnologia social "sarau empreendedor” tem potencial de transformar comunidades no desenvolvimento da identidade territorial, das manifestações artísticas, do fomento ao empreendedorismo cultural, do estímulo à realização de processos e eventos de caráter educativo e que promovam sociabilidade e no desenvolvimento social, em específico da economia local como um todo.

O sarau como processo e espaço de capacitações, sociabilidade e diversão é uma tecnologia estimuladora do protagonismo juvenil no campo da cultura. Valeu-se do exemplo da comunidade do Nordeste de Amaralina (Salvador, Bahia) neste artigo, mas essa tecnologia pode ser utilizada e aplicada em qualquer contexto que deseje capacitar jovens para atuar como empreendedores culturais por meio de uma pedagogia artística e de um processo que engaje a participação social. Além disso, quando se pensa a identidade territorial como combustível para o empreendedorismo cultural e se incluem casos já existentes de empreendedores culturais que nascem a partir da identidade territorial, essas são duas estratégias fundamentais para que o sarau desperte interesse e ganhe impulso em uma comunidade.

Entre as diversas repercussões do sarau empreendedor, espera-se que o aumento de apresentações artísticas na comunidade forme plateias para espetáculos artísticos, bem como o turismo de base comunitária, que valoriza a identidade territorial (BARTHOLO; SANSOLO; BURSZTYN, 2009). Além disso, com a união artística de comunidades distintas, é possível fortalecer as economias desses locais, ocasionando um desenvolvimento social como um todo, nos âmbitos da saúde, do trabalho, da educação, da moradia e da cultura.

Essas são as várias dimensões da contribuição prática que neste trabalho se pode oferecer por meio de seus resultados de pesquisa expressos em engajamento 
social do conhecimento produzido (como vem sendo tão valorizado por pesquisadores na área da Administração: VAN DE VEN, 2007; CUNLIFFE; SCARATTI, 2017; MASCARENHAS; ZAMBALDI; MORAES, 2011). No entanto, os resultados com este trabalho também contribuem para o avanço das pesquisas sobre ensino-aprendizagem do empreendedorismo ao proporcionarem uma compreensão específica (empreendedorismo cultural, territorial, identitária e participativa) e socialmente prática (a tecnologia social e formativa do sarau empreendedor, para além dos âmbitos universitários) da educação empreendedora.

\section{REFERÊNCIAS}

ALMEIDA, M.; PAIS, J. Criatividade e Profissionalização. Jovens, Subjetividades e Horizontes Profissionais. Lisboa: Imprensa de Ciências Sociais, 2013.

ANDERSON, A. R. Paradox in the periphery: an entrepreneurial reconstruction? Entrepreneurship \& Regional Development, v. 12, i. 2, p. 91-109, 2000.

ASSOCIAÇÃO DE MORADORES NO NORDESTE DE AMARALINA. Disponível em: <http://amnaluta.blogspot.com.br/>. Acesso em: 20 fev. 2017.

BARTHOLO, R.; SANSOLO, D.; BURSZTYN, I. (Org.) Turismo de Base Comunitária: diversidade de olhares e experiências brasileiras. Rio de Janeiro: Letra e Imagem, 2009.

BELO, F.; SCODELER, K. A importância do brincar em Winnicott e Schiller. Tempo psicanálise, v. 45, n. 1, p. 91-101, 2013.

BONDÍA, J. L. Notas sobre a experiência e o saber de experiência. Revista Brasileira de Educação, v. 19, p. 20-18, 2002.

BRANDÃO, C. A. A busca da utopia do planejamento regional. Revista Paranaense de Desenvolvimento, Curitiba, n. 120, p. 17-37, 2011.

CALAS, M. B.; SMIRCICH, L.; BOURNE, K. A. Extending the boundaries: reframing «entrepreneurship as social change» through feminist perspectives. Academy of Management Review, v. 34, i. 3, p. 552-569, 2009.

CAMPOS, I. As Músicas da Cidade: Estudos de Casos sobre o Cenário Musical Juvenil na Periferia da Cidade de Salvador. Revista Interdisciplinar de Gestão Social, v. 5, n. 3, p. 163-191, 2016. 
CASAQUI, V. A construção do papel do empreendedor social: mundos possíveis, discurso e o espírito do capitalismo. Galáxia, v. 29, p. 44-56, 2015.

CASAQUI, V. A transformação social nos discursos da cena empreendedora social brasileira: processos comunicacionais e regimes de convocação na mídia digital. Universitas Humanística, v. 81, p. 205-226, 2016.

CATACRA LIVRE. Dispon LIVRE.ma<https://catracalivre.com.br/sp/tag/sarau-da-cooperifa/> . Acesso em: 20 fev. 2017.

COLBARI, A. D. L. A análise de conteúdo e a pesquisa empírica qualitativa. In: MOULIN DE SOUZA, E. (Ed.). Metodologias e analíticas qualitativas em pesquisa organizacional. Vitória: EDUFES, 2014.

CUNLIFFE, A. L.; SCARATTI, G. Embedding Impact in Engaged Research: Developing Socially Useful Knowledge Through Dialogical Sensemaking. British Journal of Management, v. 28, i. 1, p. 22-44, 2017.

DAGNINO, R. Tecnologia social: contribuições conceituais e metodológicas. Campina Grande: Ed. Universidade Estadual da Paraíba; Florianópolis: Insular, 2014.

DANDRIDGE, T. C. Ceremony as an integration of work and play. Organization Studies, v. 7, i. 2, p. 159-170, 1986.

DAVEL, E.; CORÁ, M. A. J. Empreendedorismo cultural: cultura como recurso retórico, processo de criação e de consumo simbólico. Políticas Culturais em Revista, v. 9, n. 1, p. 363-397, 2016.

DAVEL, E.; SANTOS, F. P.; DANTAS, M. Identidade Cultural de Territórios como Política de Gestão. ENCONTRO DA ASSOCIAÇÃO NACIONAL DE POS-GRADUAÇÃO E PESQUISA EM ADMINISTRAÇÃO, 40., 2016, Costa do Sauípe.

Anais... Costa do Sauípe : Enanpad, 2016.

DM DE BOA Facebook. Disponível em: <https://www.facebook.com/DM-DE-BOA-1042522005762646/>. Acesso em: 20 fev. 2017.

DOLABELA, F. Pedagogia do Empreendedorismo. São Paulo: Cultura, 2003.

DUARTE JUNIOR, J. F. Porque a arte-educação? Campinas: Papirus, 2008. 
FAYOLLE, A. (Ed.). Handbook of research in entrepreneurship education, volume 1: a general perspective. Cheltenham: Edward Elgared, 2007.

FAYOLLE, A. (Ed.). Handbook of research in entrepreneurship education, volume 3: international perspectives. Cheltenham: Edward Elgared, 2010.

FERREIRA, F. Economia Criativa. In: BOULLOSA, R. (Org.). Dicionário para a Formação em Gestão Social. Salvador: Ed. UFBA, 2014.

FRANCISCO NETO, J. Kassab fecha o cerco sobre saraus da periferia. Brasil de Fato, 20 jun. 2012. Disponível em: <http://antigo.brasildefato.com.br/node/9808>. Acesso em: 20 fev. 2017.

FREIRE, P. Pedagogia do Oprimido. Rio de Janeiro: Paz e Terra, 2011.

GIELNIK, M. M. et al. Action and Action-Regulation in Entrepreneurship: Evaluating a Student Training for Promoting Entrepreneurship. Academy of Management Learning \& Education, v. 14, i. 1, p. 69-94, 2015.

GUARINELLO, N. Festa, trabalho e cotidiano. In: JANCSO, I.; KANTOR, I. (Org.). Festa: cultura e sociabilidade na América Portuguesa. São Paulo: Edusp: Fapesb: Imprensa Oficial, 2001. v. 2.

HALL, S. Identidade Cultural Na Pós-Modernidade. Rio de Janeiro: DP\&A, 2006.

HENRY, C.; BRUIN, A. D. (Ed.). Entrepreneurship and the creative economy: process, practice and policy. Cheltenham: Edward Elgared, 2011.

HIGGINS, D.; ELLIOTT, C. Learning to make sense: what works in entrepreneurial education? Journal of European Industrial Training, v. 35, i. 4, p. 345-367, 2011.

HJORTH, D. Creating space for play/invention: concepts of space and organizational entrepreneurship. Entrepreneurship \& Regional Development, v. 16, i. 5, p. 413-432, 2004.

HJORTH, D. Public entrepreneurship: desiring social change, creating sociality. Entrepreneurship \& Regional Development, v. 25, i. 1-2, p. 34-51, 2013.

ILÊ AIYÊ OFICIAL. DisponÊvel em: <http://www.ileaiyeoficial.com/>. Acesso em: 20 fev. 2017. 
KURATKO, D. F. The emergence of entrepreneurship education: Development, trends, and challenges. Entrepreneurship: Theory \& Practice, v. 29, i. 5, p. 577-597, 2005.

LINDQVIST, K. Artist entrepreneurs. In: SCHERDIN, M. ; ZANDER, I. (Ed.). Art entrepreneurship. Cheltenham: Edward Elgar Publishing, 2011.

LIVINGSTONE, D. Exploring the icebergs of adult learning. Canadian Journal for the Study of Adult Education, v. 3, i. 2, p. 49-72, 1999.

LOPES, R. M. A. (Ed.). Educação empreendedora: conceitos, modelos e práticas. Rio de Janeiro: Elsevier: SEBRAEed, 2010.

LOUNSBURY, M.; GLYNN, M. A. Cultural Entrepreneurship: Stories, Legitimacy, and the Acquisition of Resources. Strategic Management Journal, v. 22, i. 6/7, p. 545-564, 2001.

MAINEMELIS, C.; RONSON, S. Ideas are born in fields of play: towards a theory of play and creativity in organizational settings. Research in Organizational Behavior, v. 27, p. 81-131, 2006.

MALO, M.; RODRIGUES, A. L. Estruturas de governança e empreendedorismo coletivo: o caso dos doutores da alegria. Revista de Administração Contemporânea, v. 10, p. 29-50, 2006.

MASCARENHAS, A. O.; ZAMBALDI, F.; MORAES, E. A. Rigor, relevância e desafios da academia em administracão: tensões entre pesquisa e formação profissional. Revista de Administração de Empresas, v. 51, n. 3, p. 265-279, 2011.

MENEZES, M. Disponível em: <http://www.margarethmenezes.com.br/fabrica. aspx>. Acesso em: 20 fev. 2017.

NECK, H. M.; GREENE, P. G.; BRUSH, C. G. Teaching entrepreneurship: a practice-based approach. Cheltenham: Edward Elgar, 2014.

NEOJIBA. Disponível em: <http://neojiba.org/> . Acesso em: 20 fev. 2017.

PEÇANHA, E. de N. É tudo nosso! Produção cultural na periferia paulistana. 2012. Tese (Doutorado em Antropologia Social)-Universidade de São Paulo, São Paulo, 2012. 
PIRATAS Urbanos e roda de capoeira encerram temporada de saraus. Periferia em Movimento, 07 dez. 2016. Disponível em: <http://periferiaemmovimento.com.br/ tag/saraus/>. Acesso em: 20 fev. 2017.

PRACATUM. Disponível em: <http://www.pracatum.org.br/projetos-especiais/desenvolvimento-comunitario/apresentacao/>. Acesso em: 20 fev. 2017.

QUABALES. Disponível em: <http://quabales.com/>. Acesso em: 20 fev. 2017.

REIS, A. C. (Org.). Economia criativa como estratégia de desenvolvimento: uma visão dos países em desenvolvimento. São Paulo: Itaú Cultural, 2008.

RENTSCHLER, R. Painting equality: female artists as cultural entrepreneurial marketers. Equal Opportunities International, v. 26, i. 7, p. 665-677, 2007.

RINDOVA, V.; BARRY, D.; KETCHEN, D. J. Entrepreneuring as emancipation. Academy of Management Review, v. 34, i. 3, p. 477-491, 2009.

RODRIGUES, I.; BARBIERI, J. C. A emergência da tecnologia social: revisitando o movimento da tecnologia apropriada como estratégia de desenvolvimento sustentável. Revista de Administração Pública, v. 42, i. 6, p. 1069-1094, 2008.

SALAZAR, L. Música Ltda.: o negócio da música para empreendedores. Recife: Sebrae, 2015.

SARAU DA ONÇA. Disponível em: <http://saraudaonca.blogspot.com.br/>. Acesso em: 20 fev. 2017.

SCHMIDT, C. M. et al. O empreendedorismo coletivo no contexto do turismo rural sustentável: uma experiência do Sul do Brasil. Revista de Turismo y Patrimonio Cultural, v. 14, n. 5, p. 1161-1174, 2016.

SCOTT, M. Cultural entrepreneurs, cultural entrepreneurship. Poetics, v. 40, p. 237255, 2012.

STEYAERT, C.; HJORTH, D. (Ed.). Entrepreneurship as social change. Cheltenham: Edward Elgar, 2006.

SWEDBERG, R. Entrepreneurship: The Social Science View. Oxford: Oxford University Press, 2000. 
TENNINA, L. Saraus das periferias de São Paulo: poesia entre tragos, silêncios e aplausos. Estudos de Literatura Brasileira Contemporânea, n. 1, p. 11-28, 2013.

TRANSFORMA. Disponível em: <http://www.transforma.org.pt/pt/>. Acesso em: 20 fev. 2017.

VAN DE VEN, A. H. Engaged scholarship: a guide for organizational and social research. Oxford: Oxford University Press, 2007.

VIANNA, B. Saraus transformam periferia em centro. Acesso, 31 jul. 2012. Notícias. Disponível em: <http://www.blogacesso.com.br/?p=5264>. Acesso em: 20 fev. 2017.

WINNICOTT, D. W. O brincar e a realidade. Rio de Janeiro: Imago, 1975.

\section{Como citar este artigo:}

\section{ABNT}

CAMPOS, Israel Marques; DAVEL, Eduardo. Identidade, Arte e Gestão em prol do Empreendedorismo Cultural: Sarau Empreendedor como Tecnologia Social. RACE, Revista de Administração, Contabilidade e Economia, Joaçaba: Ed. Unoesc, v. 16, n. 2, p. 783-808, maio/ago. 2017. Disponível em: <http://editora.unoesc.edu.br/ index.php/race>. Acesso em: dia/mês/ano.

APA

Campos, I. M., \& A. A. de, \& Davel, E. (2017). Identidade, Arte e Gestão em prol do Empreendedorismo Cultural: Sarau Empreendedor como Tecnologia Social. RACE, Revista de Administração, Contabilidade e Economia, 16(2), 783-808. Recuperado em dia/mês/ano, de http://editora.unoesc.edu.br/index.php/race 
